\title{
Synthetic double-stranded RNA induces retinoic acid-inducible gene-I in mouse osteoblastic cells
}

\author{
KIMIYA NAKAMURA ${ }^{1}$, YOSHIAKI DEYAMA ${ }^{2}$, YOSHITAKA YOSHIMURA ${ }^{2}$, \\ KUNIAKI SUZUKI ${ }^{2}$ and MANABU MORITA ${ }^{3}$ \\ ${ }^{1}$ Comprehensive Conservative Dentistry, Hokkaido University Hospital, Kita 14 Nishi 5, Kita-ku, \\ Sapporo 060-8648; Departments of ${ }^{2}$ Molecular Cell Pharmacology, Division of Oral Pathobiological Science, \\ ${ }^{3}$ Preventive Dentistry, Division of Oral Health Science, Hokkaido University Graduate School of \\ Dental Medicine, Kita 13 Nishi 7, Kita-ku, Sapporo 060-8586, Japan
}

Received July 17, 2008; Accepted September 19, 2008

DOI: 10.3892/mmr_00000036

\begin{abstract}
Retinoic acid inducible gene-I (RIG-I) is a member of the DExH box family of proteins. RIG-I acts as a sensor of viral infections through the recognition of viral double-stranded RNA (dsRNA). Recently, it was demonstrated that polyinosinic acid:polycytidylic acid [poly(I):poly(C)], a synthetic dsRNA analogue, induced the expression of RIG-I in various cell types, such as vascular endothelial cells and gingival fibroblasts. However, it remains unclear whether RIG-I is induced in osteoblasts in response to poly(I):poly $(\mathrm{C})$. In the present study, we investigated the effects of poly(I):poly(C) on the expression of RIG-I in mouse osteoblastic MC3T3-E1(E1) cells. We found that $\operatorname{poly}(\mathrm{I})$ :poly $(\mathrm{C})$ increased the expression level of RIG-I in $E 1$ cells, and that recombinant interferon- $\beta$ (IFN- $\beta$ ) induced the expression of RIG-I mRNA in E1 cells. An anti-IFN- 3 neutralizing antibody partially inhibited poly(I):poly(C)-induced RIG-I expression. These results indicate that RIG-I production is induced by poly(I):poly(C)-provoked IFN- $\beta$ in mouse osteoblastic E1 cells. We suggest that osteoblasts are involved in antiviral defense as well as in bone metabolism. Results of further studies will provide more clues regarding the molecular function of osteoblasts in viral infection.
\end{abstract}

\section{Introduction}

Retinoic acid inducible gene-I (RIG-I), which has been classified as a member of the DExH box protein family, contains a C-terminal helicase domain and two caspase

Correspondence to: Dr Yoshiaki Deyama, Department of Molecular Cell Pharmacology, Division of Oral Pathobiological Science, Hokkaido University Graduate School of Dental Medicine, Kita 13 Nishi 7, Kita-ku, Sapporo 060-8586, Japan

E-mail: dey@den.hokudai.ac.jp

Key words: osteoblast, polyinosinic acid:polycytidylic acid, retinoic acid inducible gene-I, interferon- $\beta$ recruitment domains (CARDs) at its $\mathrm{N}$-terminus. The helicase domain is involved in recognizing viral double-stranded RNA (dsRNA), while the CARDs apparently mediate signals leading to the activation of $\mathrm{NF}-\mathrm{\kappa B}$ and interferon regulatory factor-3 (IRF-3) on binding with dsRNA $(1,2)$. Recently, it was demonstrated that polyinosinic acid:polycytidylic acid [poly(I):poly(C)], a synthetic dsRNA analogue, induced the expression of RIG-I in various cell types, such as vascular endothelial cells and gingival fibroblasts $(3,4)$.

Osteoblasts are specialized cells responsible for bone formation in vertebrates. They produce bone matrix proteins including type I collagen, osteocalcin, osteopontin and bone sialoprotein. Most of these bone matrix proteins are secreted and deposited by mature osteoblasts $(5,6)$.

Toll-like receptor 3 (TLR3) recognizes double-stranded RNA and its mimic poly(I):poly(C) (7). RIG-I is also defined as a dsRNA-binding protein, but its functions are independent of TLR3 $(1,8)$. We recently demonstrated that TLR3, which was up-regulated by poly(I):poly(C), was expressed in the mouse osteoblastic cell line MC3T3-E1 (E1), and that poly(I): poly $(\mathrm{C})$ increased the expression levels of interferon- $\beta$ (IFN- $\beta$ ) mRNA in E1 cells (9). However, it remains unclear whether RIG-I is induced in osteoblasts in response to poly(I):poly(C).

In the present study, we investigated the effect of poly(I): poly $(\mathrm{C})$ on the expression of RIG-I in mouse osteoblastic E1 cells. We demonstrated that poly(I):poly(C) increased the expression level of RIG-I in E1 cells. Therefore, we examined the effect of IFN- $\beta$ on RIG-I expression in E1 cells.

\section{Materials and methods}

Reagents. Poly(I):poly(C) was obtained from GE Biosciences (Piscataway, NJ). Recombinant mouse IFN- $\beta$ and rabbit polyclonal antibody against mouse IFN- $\beta$ were purchased from PBL Biomedical Laboratories (New Brunswick, NJ).

Cell culture. Osteoblastic E1 cells from mouse calvaria were cultured in $\alpha$-minimum essential medium ( $\alpha$-MEM; Wako Pure Chemical Industries Ltd., Osaka, Japan) supplemented with $10 \%$ fetal bovine serum (FBS; ICN Biomedicals Inc., $\mathrm{OH})$, ascorbic acid $(50 \mu \mathrm{g} / \mathrm{ml})$ and kanamycin $(60 \mu \mathrm{g} / \mathrm{ml}$; 
$\mathbf{A}$

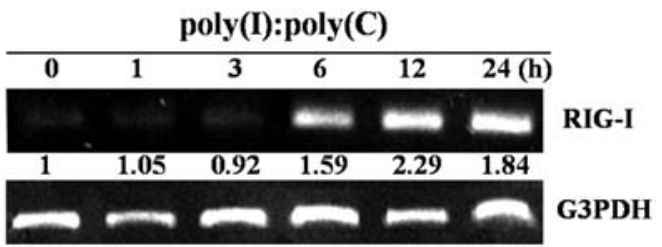

B

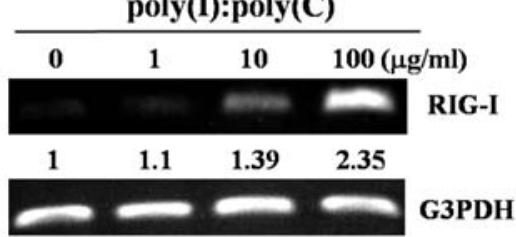

Figure 1. Poly(I):poly $(\mathrm{C})$ induced the expression of RIG-I mRNA in MC3T3-E1 cells. (A) E1 cells were cultured in $\alpha$-MEM with $100 \mu \mathrm{g} / \mathrm{ml}$ poly(I):poly(C) for the indicated periods, and total RNA was analyzed by RT-PCR with specific primers described in Materials and methods. G3PDH was used as an internal control. Fold increase at the bottom of the signals represents the intensity of RIG-I mRNA expression relative to G3PDH. (B) E1 cells were exposed to various concentrations of poly(I):poly(C) for $6 \mathrm{~h}$. Levels of RIG-I and G3PDH mRNA were determined as described in (A).

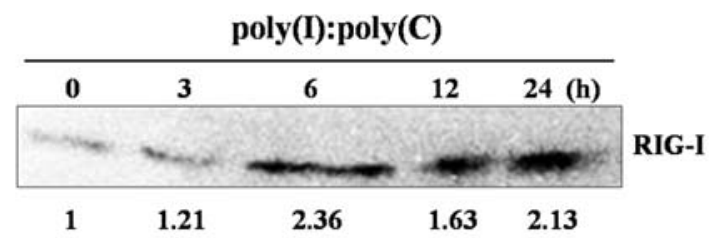

Figure 2. E1 cells were stimulated with $100 \mu \mathrm{g} / \mathrm{ml}$ poly(I):poly(C) for various periods, and whole cell lysates were extracted and subjected to $10 \%$ SDS-PAGE. RIG-I protein was visualized with anti-RIG-I antibody and an enhanced chemiluminescence system. Values at the bottom of the signals indicate the intensity of RIG-I protein expression.

Meijiseika, Tokyo, Japan). Cultures were maintained at $37^{\circ} \mathrm{C}$ in a humidified atmosphere with $5 \% \mathrm{CO}_{2}$. After confluence, $\mathrm{E} 1$ cells were treated with poly(I): $\operatorname{poly}(\mathrm{C})$ or IFN-B.

$R T$-PCR. Total RNA from E1 cells was prepared using Trizol solution (Invitrogen, Carlsbad, CA) according to the manufacturer's protocol. First-strand cDNA was synthesized from total RNA with ReverTra Ace (Toyobo, Osaka, Japan) and was subjected to PCR amplification with AmpliTaq Gold DNA polymerase (Roche Molecular Systems, Braunchburg, NJ). Sequences of the primers used for PCR were as follows: RIG-I, 5'-GCA TAT TGA CTG GAC GTG GCA-3' and 5'CAG TCA TGG GTG CAG TTC TGT C-3'; and glyceraldehyde-3-phosphate dehydrogenase (G3PDH), 5'-CGG AGT CAA CGG ATT TGG TCG TAT-3' and 5'-AGC CTT CTC CAT GGT GGT GAA GAC-3'. Amplification was conducted for 23-32 cycles. All PCRs were within the exponential amplification range. The annealing temperatures of RIG-I and G3PDH were 55 and $60^{\circ} \mathrm{C}$, respectively. After amplification, the synthesized PCR products were separated by electrophoresis on a $1 \%$ agarose gel and visualized by ethidium bromide staining. The level of expression of RIG-I mRNA was analyzed with Scion Image (Scion Corp., Frederick, MD) and normalized with G3PDH mRNA expression.
$\mathbf{A}$

\begin{tabular}{|c|c|c|c|c|c|c|}
\hline \multicolumn{6}{|c|}{ IFN- $\beta$} & \\
\hline 0 & 1 & 3 & 6 & 12 & $24(h)$ & \\
\hline 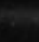 & 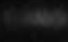 & Ex & 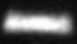 & as & - & RIG-I \\
\hline 1 & 1.05 & 2.72 & 2.18 & 1.86 & 1.5 & \\
\hline 6 & & & 6 & sines & 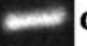 & G3PDH \\
\hline
\end{tabular}

B

\begin{tabular}{|c|c|c|c|c|}
\hline \multicolumn{5}{|c|}{ IFN- $\beta$} \\
\hline $\mathbf{0}$ & 10 & 100 & $1000(\mathrm{U} / \mathrm{m}$ & \\
\hline $\cos 2$ & cones: & cos & 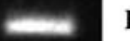 & RIG-I \\
\hline 1 & 1.1 & 1.5 & 1.81 & \\
\hline 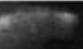 & & $5=$ & & $S P D$ \\
\hline
\end{tabular}

Figure 3. Exogenous IFN- $\beta$ induced the expression of RIG-I mRNA in E1 cells. (A) E1 cells were cultured in $\alpha$-MEM with $1000 \mathrm{U} / \mathrm{ml}$ recombinant mouse IFN- $\beta$, and total RNA was analyzed by RT-PCR with specific primers described in Materials and methods. (B) E1 cells were cultured with various concentrations of IFN- $\beta$ for $6 \mathrm{~h}$, and then RIG-I and G3PDH mRNA were analyzed by RT-PCR. Fold increase at the bottom of the signals represents the intensity of RIG-I mRNA expression relative to G3PDH.

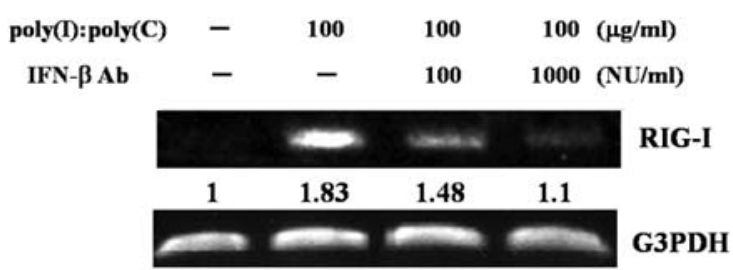

Figure 4. E1 cells were cultured with or without various concentrations of neutralizing antibody against IFN- $\beta$ and $100 \mu \mathrm{g} / \mathrm{ml}$ poly(I):poly(C) for $6 \mathrm{~h}$. RIG-I and G3PDH mRNA expression was analyzed by RT-PCR using specific primers described in Materials and methods. Values at the bottom of the RIG-I mRNA images were normalized against expression of the G3PDH gene.

Western blot analysis. After stimulation with poly(I):poly(C) for various time intervals, E1 cells were washed twice with PBS and then treated with lysis buffer [10 mM HEPES-KOH (pH 7.5), $100 \mathrm{mM} \mathrm{KCl}$ and 0.1\% NP-40]. Protein concentration in the cell lysate was measured using a BioRad Protein Assay Kit (BioRad, Hercules, CA). Each sample containing equal amounts of protein was separated by $10 \%$ SDS-polyacrylamide gel electrophoresis (SDS-PAGE) and transferred to a polyvinylidene difluoride membrane (Millipore, Bedford, MA). After being blocked with 5\% skim milk in Tris-buffered saline containing $0.1 \%$ Tween-20 (TBST), the membrane was incubated with anti-RIG-I antibodies and subsequently with HRP-conjugated anti-mouse or anti-rabbit IgG antibody. Immunoreactive proteins were visualized with Western blot chemiluminescence reagents (Perkin Elmer Life Sciences, Boston, MA) following the manufacturer's instructions.

\section{Results}

Polyinosinic acid:polycytidylic acid increases RIG-I mRNA expression levels in osteoblastic E1 cells. We examined the induction of RIG-I mRNA expression in E1 cells by poly(I): poly $(\mathrm{C})$. As shown in Fig. 1A, poly(I):poly(C) markedly increased the RIG-I mRNA expression level in E1 cells. The 
increase was apparent as early as $6 \mathrm{~h}$ after adding poly(I): poly $(\mathrm{C})$ to the culture and peaked at $12 \mathrm{~h}$. As shown in Fig. 1B, the effect of poly(I):poly(C) on RIG-I mRNA was dosedependent. The increase in RIG-I mRNA level was slightly enhanced at $10 \mu \mathrm{g} / \mathrm{ml} \operatorname{poly}(\mathrm{I})$ :poly(C), and the maximal response was obtained at $100 \mu \mathrm{g} / \mathrm{ml}$.

Polyinosinic acid:polycytidylic acid up-regulates production of RIG-I protein in osteoblastic El cells. To determine whether poly(I):poly $(\mathrm{C})$ induces the production of RIG-I protein by $\mathrm{E} 1$ cells, total cellular protein was isolated at various times after stimulation with poly(I):poly $(\mathrm{C})$, and the expression of RIG-I protein was analyzed by Western blotting. Concomitant with the induction of RIG-I mRNA expression, the results of Western blot analysis reveal that the expression level of RIG-I protein in E1 cells was markedly increased by poly(I):poly(C) treatment (Fig. 2).

Interferon- $\beta$ induces expression of RIG-I mRNA in osteoblastic E1 cells. In a recent study, we demonstrated that poly(I): poly $(C)$ induced IFN-B mRNA in osteoblastic E1 cells (9). Therefore, we now investigated whether exogenous IFN- $\beta$ could increase levels of RIG-I mRNA in osteoblastic cells. As shown in Fig. 3A, exogenous IFN- 3 markedly induced RIG-I mRNA expression levels in E1 cells, increasing them $3 \mathrm{~h}$ after stimulation. Moreover, RIG-I mRNA expression was clearly observed at $100 \mathrm{U} / \mathrm{ml}$; the maximal level was obtained at $1000 \mathrm{U} / \mathrm{ml} \mathrm{IFN- \beta} \mathrm{(Fig.} \mathrm{3B).}$

Anti-mouse interferon- $\beta$ antibody partially inhibits polyinosinic acid:polycytidylic acid-induced RIG-I mRNA expression in osteoblastic E1 cells. To determine whether IFN- $\beta$ was responsible for poly(I):poly(C)-induced RIG-I expression, E1 cells were incubated with $100 \mu \mathrm{g} / \mathrm{ml} \operatorname{poly}(\mathrm{I})$ :poly(C) for $6 \mathrm{~h}$ in the presence or absence of anti-IFN- $\beta$ neutralizing antibody. Fig. 4 shows that anti-IFN- $\beta$ antibody reduced poly(I):poly(C)induced RIG-I mRNA expression levels, indicating that poly(I):poly(C)-induced endogenous IFN- $\beta$ was responsible for this effect.

\section{Discussion}

Osteoblasts are responsible for bone metabolism. Recently, we demonstrated that they are also involved in antiviral innate immunity through TLR3 (9). RIG-I is a cytoplasmic RNA helicase that contains tandem motifs near its N-terminus with limited homology to the CARD and a downstream DExH box helicase domain. Like TLR3, RIG-I recognizes viral dsRNA. The binding of viral dsRNA leads to a conformational change that exposes the N-terminal CARDs, a process essential if RIG-I is to function as a signal transducer $(1,10)$. Viral signaling through RIG-I and its adaptor protein, IFN promoterstimulator 1 (IPS-1), activates IFN regulatory factor-3 (IRF-3) and the host IFN- $\alpha / \beta$ response that limits viral infections (11). Recently, it was demonstrated that $\operatorname{poly}(\mathrm{I})$ : $\operatorname{poly}(\mathrm{C})$ induced the expression of RIG-I in various cell types, such as vascular endothelial cells and gingival fibroblasts $(3,4)$. However, in osteoblasts there have been no reports on the relation between dsRNA and RIG-I. Therefore, we examined the effect of poly(I):poly(C) on mouse osteoblastic E1 cells. RIG-I mRNA and protein expression were induced in $\operatorname{poly}(\mathrm{I})$ :poly $(\mathrm{C})$ - stimulated mouse osteoblastic E1 cells. This suggests that RIG-I may play an important role in antiviral response in osteoblasts. Moreover, double-stranded RNA-dependent protein kinase (PKR) and melanoma differentiation-associated gene 5 (MDA-5) recognize dsRNA $(12,13)$. The relationship between PKR and osteoblasts has been previously studied $(14,15)$. However, the effects of poly(I):poly(C) on the expression of MDA-5 in osteoblasts have not yet been elucidated. Further studies on MDA-5 are needed to clarify the ability of osteoblasts in an antiviral response.

Sirén et al revealed that RIG-I gene and protein expression was greatly enhanced by IFN- $\alpha$ or $-\beta$ stimulation of A549 epithelial cells (16). Moreover, we demonstrated that poly(I): poly $(\mathrm{C})$ markedly increased IFN- $\beta$ mRNA expression levels in osteoblastic E1 cells (9). Thus, we investigated whether IFN- $\beta$ could increase the level of RIG-I mRNA in osteoblastic cells. In the present study, we demonstrated that recombinant IFN- $B$ induced expression of RIG-I mRNA in E1 cells, and that poly(I):poly(C)-induced RIG-I mRNA was partially inhibited by an anti-IFN- $\beta$ neutralizing antibody. These results indicate that the release of IFN- $\beta$ from E1 cells by poly(I):poly $(\mathrm{C})$ stimulation up-regulates RIG-I in an autocrine manner. One classic mechanism employed by IFNs is the JAK-STAT signaling pathway for inducing cellular response (17). In a recent study, we found that $\operatorname{poly}(\mathrm{I})$ :poly $(\mathrm{C})$ induced STAT1 activation, which was blocked by anti-IFN- $\beta$ neutralizing antibody in osteoblastic E1 cells (9). Thus, subsequent investigation of whether poly(I):poly $(\mathrm{C})$-induced RIG-I in osteoblastic cells is dependent on STAT1 activation is required.

In summary, we demonstrated the effects of polyinosinic acid:polycytidylic acid on the expression of retinoic acid inducible gene-I in mouse osteoblastic MC3T3-E1 cells. It is possible that poly(I):poly $(C)$ first induces interferon- $\beta$ in response to viral infection, and that endogenous IFN- $\beta$ enhances RIG-I expression in mouse E1 cells. We suggest that osteoblasts are involved in antiviral defense through Toll-like receptor 3 and RIG-I, as well as through bone metabolism. Results of further studies will provide more clues regarding the molecular function of osteoblasts in viral infection.

\section{References}

1. Yoneyama M, Kikuchi M, Natsukawa T, Shinobu N, Imaizumi T, Miyagishi M, Taira K, Akira S and Fujita T: The RNA helicase RIG-I has an essential function in double-stranded RNA-induced innate antiviral responses. Nat Immunol 5: 730-737, 2004.

2. Sumpter RJ, Loo YM, Foy E, Li K, Yoneyama M, Fujita T, Lemon SM and Gale MJ: Regulating intracellular antiviral defense and permissiveness to hepatitis C virus RNA replication through a cellular RNA helicase, RIG-I. J Virol 79: 2689-2699, 2005.

3. Imaizumi T, Hatakeyama M, Yamashita K, Ishikawa A, Yoshida H, Satoh K, Taima K, Mori F and Wakabayashi K: Double-stranded RNA induces the synthesis of retinoic acidinducible gene-I in vascular endothelial cells. Endothelium 12: 133-137, 2005.

4. Kubota K, Sakaki H, Imaizumi T, Nakagawa H, Kusumi A, Kobayashi W, Satoh K and Kimura H: Retinoic acid-inducible gene-I is induced in gingival fibroblasts by lipopolysaccharide or poly IC: possible roles in interleukin-1ß, -6 and -8 expression. Oral Microbiol Immunol 21: 399-406, 2006.

5. Young MF, Kerr JM, Ibaraki K, Heegaard AM and Robey PG: Structure, expression, and regulation of the major non-collagenous matrix proteins of bone. Clin Orthop Relat Res 281: 275-294, 1992.

6. Chen J, Shapiro HS and Sodek J: Development expression of bone sialoprotein mRNA in rat mineralized connective tissues. J Bone Miner Res 7: 987-997, 1992. 
7. Alexopoulou L, Holt AC, Medzhitov R and Flavell RA: Recognition of double-stranded RNA and activation of NF- $\mathrm{kB}$ by Tolllike receptor 3. Nature 413: 732-738, 2001.

8. Meylan E and Tschopp J: Toll-like receptors and RNA helicases: two parallel ways to trigger antiviral responses. Mol Cell 22: 561-569, 2006.

9. Nakamura K, Deyama Y, Yoshimura Y, Suzuki K and Morita M: Toll-like receptor 3 ligand-induced antiviral response in mouse osteoblastic cells. Int J Mol Med 19: 771-775, 2007.

10. Yoneyama M, Kikuchi M, Matsumoto K, Imaizumi T, Miyagishi M, Taira K, Foy E, Loo YM, Gale M Jr, Akira S, Yonehara S, Kato A and Fujita T: Shared and unique functions of the DExD/H-box helicases RIG-I, MDA5, and LGP2 in antiviral innate immunity. J Immunol 175: 2851-2858, 2005.

11. Loo YM, Owen DM, Li K, Erickson AK, Johnson CL, Fish PM, Carney DS, Wang T, Ishida H, Yoneyama M, Fujita T, Saito T, Lee WM, Hagedorn CH, Lau DT-Y, Weinman SA, Lemon SM and Gale M Jr: Viral and therapeutic control of IFN-B promoter stimulator 1 during hepatitis $\mathrm{C}$ virus infection. Proc Natl Acad Sci USA 103: 6001-6006, 2006.

12. Katze MG, Wambach M, Wong ML, Garfinkel M, Meurs E, Chong K, Williams BR, Hovanessian AG and Barber GN: Functional expression and RNA binding analysis of the interferoninduced, double-stranded RNA-activated, $68,000-\mathrm{Mr}$ protein kinase in a cell-free system. Mol Cell Biol 11: 5497-5505, 1991.
13. Kang DC, Gopalkrishnan RV, Wu Q, Jankowsky E, Pyle AM and Fisher PB: mda-5: An interferon-inducible putative RNA helicase with double-stranded RNA-dependent ATPase activity and melanoma growth-suppressive properties. Proc Natl Acad Sci USA 99: 637-642, 2002.

14. Yoshida K, Okamura H, Amorim BR, Ozaki A, Tanaka H, Morimoto T and Haneji T: Double-stranded RNA-dependent protein kinase is required for bone calcification in MC3T3-E1 cells in vitro. Exp Cell Res 311: 117-125, 2005.

15. Morimoto H, Ozaki A, Okamura H, Yoshida K, Kitamura S and Haneji T: Okadaic acid induces tyrosine phosphorylation of I $\mathrm{B} \alpha$ that is mediated by PKR pathway in human osteoblastic MG63 cells. Mol Cell Biochem 276: 211-217, 2005.

16. Sirén J, Imaizumi T, Sarkar D, Pietilä T, Noah DL, Lin R, Hiscott J, Krug RM, Fisher PB, Julkunen I and Matikainen S: Retinoic acid inducible gene-I and mda-5 are involved in influenza A virus-induced expression of antiviral cytokines. Microbes Infect 8: 2013-2020, 2006.

17. Levy DE and JE Darnell Jr: Stats: transcriptional control and biological impact. Nat Rev Mol Cell Biol 3: 651, 2002. 